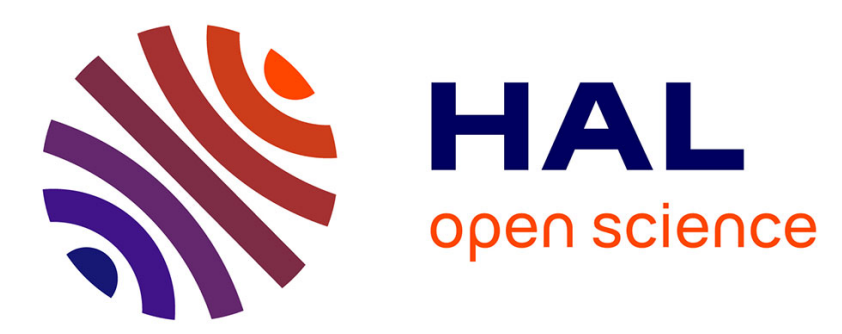

\title{
Power operation with reduced heat transmitting tiles at Tore Supra
}

\author{
R. Mitteau, J. Schlosser, M. Lipa, A. Durocher
}

\section{To cite this version:}

R. Mitteau, J. Schlosser, M. Lipa, A. Durocher. Power operation with reduced heat transmitting tiles at Tore Supra. Journal of Nuclear Materials, 2009, 386-388, pp.844 - 846. 10.1016/j.jnucmat.2008.12.260 . cea-02942091

\section{HAL Id: cea-02942091 https://hal-cea.archives-ouvertes.fr/cea-02942091}

Submitted on 17 Sep 2020

HAL is a multi-disciplinary open access archive for the deposit and dissemination of scientific research documents, whether they are published or not. The documents may come from teaching and research institutions in France or abroad, or from public or private research centers.
L'archive ouverte pluridisciplinaire HAL, est destinée au dépôt et à la diffusion de documents scientifiques de niveau recherche, publiés ou non, émanant des établissements d'enseignement et de recherche français ou étrangers, des laboratoires publics ou privés. 
This a postprint (paper accepted for publication, after peer review) of :

R. Mitteau, J. Schlosser, M. Lipa, A. Durocher,

Power operation with reduced heat transmitting tiles at tore supra,

Journal of Nuclear Materials, Volumes 386-388,2009,Pages 844-846,

ISSN 0022-3115,

https://doi.org/10.1016/i.jnucmat.2008.12.260

http://www.sciencedirect.com/science/article/pii/S0022311508009999

\title{
POWER OPERATION WITH REDUCED HEAT TRANSMITTING TILES AT TORE SUPRA
}

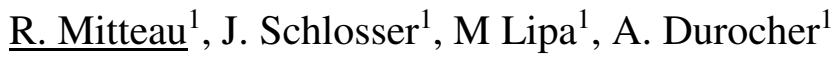 \\ ${ }^{1}$ Association Euratom-CEA, CEA/DSM/DRFC, Centre de Cadarache, 13108 Saint-Paul-Lez- \\ Durance, France
}

\section{Abstract}

Three lagging tiles - over 12054 - are present since 2006 on Tore Supra main limiter, an actively cooled high heat flux plasma facing component. The deterioration is attributed to progressing cracking of the bond between the tiles and the copper based heat sink. It is observed by an infrared camera : the thermal time constant of the tiles during cool down increased by a factor of three during the experimental campaigns of 2006 where a high level of additional power was used repetitively during long pulses. An element with a defective tile is removed for inspection during the summer shut down of 2007. The bond is cracked on three quarters of the length. Although the defects are important, the defective tiles do not limit the operation.

\section{Introduction}

Tore Supra (TS) operates since 2001 with an actively cooled toroidal pump limiter (TPL) located in the bottom of the vacuum vessel as the main plasma-facing component [1,2]. The TPL is made of 574 high heat flux individual finger elements, arranged in 12 sectors of 48 . Each sector covers a toroidal angle of $30^{\circ}$ (for the supporting through a beam which is also the manifold). The finger elements have a water channel allowing thermal steady state in 3 seconds (the time constant $\tau$ is $\sim 1 \mathrm{~s}$ ). The TPL has enabled pulses up to 6 minutes (Pinj = $3 \mathrm{MW})$, and steady state is also reached during high power operation (10 MW) with a peak heat flux of $\sim 5 \mathrm{MW} / \mathrm{m}^{2}$ (about half the design maximum heat flux of $10 \mathrm{MW} / \mathrm{m}^{2}$ ). The surface temperature is monitored by endoscopes and cameras in the infrared (IR) range. For the 2006 campaign, a new line of sight was available, aiming at a $35^{\circ}$ section not observed since its 2002 installation. The first images of this camera showed 3 lagging tiles (Fig. 1.) The best instant to observe defective tiles is the cool down after the discharge, because the 
component cools rapidly due to the circulation of water in the channels. Lagging tiles remain hotter than the structure in that process, which makes them appear clearly. This is the usual method to detect defects [3]. The three defects are observed on a section of $20^{\circ}$ of 1000 tiles, which makes a defect rate of $0.3 \%$. Considering that no lagging tile has been monitored on Q6B and Q3B lines of sight ( $2 \times 60^{\circ}$, that is 6000 tiles), the defect rate for the entire limiter decreases to $0.05 \%$. The three defectives tiles are called in the following A, B and C. The initial IR image suggests that A and B are corner defects, whereas $\mathrm{C}$ is a band defect in the radial direction. The IR image allows to determine the precise location of the lagging tiles (Fig. 2). The tile position on the element starts at 1 on the leading edge. Mechanically tile A is on the Q6A sector and B\&C on Q5B.

- $\quad$ A is on the first position of Q6A. It is element $\mathrm{N}^{\circ} 200$, and it is the tile 4 of this element.

- $\quad$ B is on the position 47 of Q5B. It is element $\mathrm{N}^{\circ} 610$, and it is tile 8 of this element.

- $\mathrm{C}$ is on the position 46 of Q5B. It is element $\mathrm{N}^{\circ} 594$, and it is the tile 10 of this element.

The positions are transferred on a heat flux map in Fig. 2. All 3 tiles are localized in a high heat load area, between the two heat flux concentrations. This area is also the one where the cross field heat flux is at its maximum, and is also the location where the ion ripple losses impinge. This can be considered an area where the heat flux is close to the TPL maximum. Investigation in the records of the non destructive examination of the finger elements prior to installation showed that the tiles were defectless at the origin, with a thermal lag $\Delta \mathrm{T}$ smaller than the acceptance criterion of $3^{\circ}$ (first line of table 1).

The detection of these tiles led to an analysis. Critical heat flux evaluations, implying a defect tile, have been performed by $2 \mathrm{D}$ calculations taking into account typical TS hydraulic operation parameters $(\mathrm{v}=9 \mathrm{~m} / \mathrm{s}$, Pout $=$ 2.4 $\mathrm{MPa}$, Tout $=135^{\circ} \mathrm{C}$ ) including radiation conditions on the defect interface. For a tile to copper interface defect of $80 \%$, the tile surface temperature is quite inhomogeneous; however the safety factor of wall critical heat flux, which is different in the two cooling channels, is around 2.8. This can be explained by the rather high thermal conductivity of copper material which spread sufficiently the local conducted heat along the corresponding tile heat sink area. Even at higher heat fluxes up to $10 \mathrm{MW} / \mathrm{m}^{2}$, where the tile surface will be locally sublimated, the critical heat flux safety factor remains around 1.8. However the bond soft copper compliant layer reaches locally unacceptable temperatures up to $620{ }^{\circ} \mathrm{C}$, implying a high probability of tile detachment. As the margin to critical heat flux is always high, even for a severely faulty tile, and that the sole risk is to de-bond a tile in operation with no risk of water leak, it was decided to proceed with the experimental campaign, however with an active monitoring of the tiles using the IR diagnostic. 


\section{Monitoring}

\subsection{Method}

The monitoring is done by analyzing the thermal time constant of the tiles $(\tau)$. This parameter has been intensively studied [4] and is well suited to characterize the heat transfer of the tile. As the heat flux on the tile is varying continuously with time during the discharge, this parameter is not simple to get. Inverse methods can be used, but such methods require an elaborated mathematic formalism which hide the tangible evolution of the thermal behavior. The choice here is to estimate $\tau$ on disruptive discharges, where the heat flux suddenly stops on the tile. As the water cooling is intense, the tile cools rapidly with an exponential decay. The time constant $\tau$ is then extracted simply by fitting a straight line though the logarithm of the temperature, and taking its slope (Fig. 3). The 5 first points $(100 \mathrm{~ms})$ are discarded to reduce the influence of short events like the energy deposited by the disruption and the artificial shortening of $\tau$ caused by superficial layers. Not all disruptions are however usable : the plateau must be sufficiently steady and the initial temperature sufficiently high to have enough dynamics of the IR signal. The location of the pick up points is given Fig. 1, along with some other reference points to precise the analysis : $\mathrm{N}$ (№rmal), d1 (deposit), d2 (another deposit area) - Fig. 1

\subsection{Results}

The analysis is done during the 2006 campaign, in which high power operation is pursued (Fig. 4). High power discharges are also the most damaging for the bond between the tile and the heat sink. Fig. 3 shows that 62 pulses over 7.5 MW and lasting at least $10 \mathrm{~s}$ are achieved during that campaign (mainly toward the end.). The value of 10 seconds is chosen on the basis that thermal steady state must have been achieved to get the full amplitude of the stress cycle on the bond - the stress cycle being the reason for crack propagation. The campaigns from 2002 to 2005 add only 25 of such shots so that most of the damage is attributed to the 2006 campaign.

The time constant is plotted against the shot number in Fig. 5. Tile A passes from $1.7 \mathrm{~s}$ to $4.4 \mathrm{~s}$, a four fold increase. Tile B increases somewhat less from $1 \mathrm{~s}$ to $2.4 \mathrm{~s}$, and tile $\mathrm{C}$ from $1 \mathrm{~s}$ to $4 \mathrm{~s}$. For the same discharge series, the normal tile undergoes no significant variation. Deposited tiles demonstrate a slow increase, from 0.5 to $0.8 \mathrm{~s}$ for the first pick-up point and from 1 to $2 \mathrm{~s}$ for the second one. These increases are attributed to deposit growth, and are still a factor of 2 smaller than the one apparently caused by bond deterioration. The error margin 
on $\tau$ is difficult to establish, still a 20 to $30 \%$ error (the one of the IR measure) is probable. This error bar is also comparable to the reproducibility of the evaluations (Fig. 5). As a result, the $\tau$ increases are significant and can not be attributed to something else but crack propagation. The slope of the increase is steady, and does not shows sign of saturation : the tiles thermal behaviour is expected to tend to the one of a radiation cooled tile. The defects are less apparent on temperature maps. Even though their stabilized temperature is up to three time hotter than regular tiles, the hot area pattern is so much dominated by the very hot carbon redeposited material that the hotter tiles do not attract attention. It should be mentioned that the defects are located in a deposition area, where the stabilized temperature is influenced by the material deposit. The time constant is less sensitive to material deposits, especially when it is evaluated with a focus on the time scale of the seconds. A comparison can still be attempted : previous modeling during the TPL design indicated that a tile with a 3 time longer $\tau$ is 2 time hotter than normal tiles at $5 \mathrm{MW} / \mathrm{m}^{2}(1470 \mathrm{~K}$ instead of $870 \mathrm{~K})$. This is indeed what is observed, within the IR accuracy of $20 \%$.

\section{Ex situ characterization}

During the summer of 2007, Q6A was temporarily removed from the torus, in order to draw 9 element samples (DITS project, aiming at deuterium trapping investigations). The occasion is used to remove the first element of the sector, containing the defect A. Once examined by the side, a crack of $75 \%$ of the bond is evidenced (Fig 6). The crack is seen on both sides, to about the same length. It indicates that the defect is certainly continuous throughout the bond. It is now a transverse band defect, and it is an evolution from the initial estimate that it was a corner defect. A thermal non destructive test is done, using the SATIR test bed (Table 1). The $\Delta \mathrm{T}_{\text {SATIR }}$ is measured to $21.8^{\circ}$. This is an increase by a factor 15 compared to the initial value, stressing how much the heat transfer has been degraded. It is remarkable to experience that the element is still functional at half its design heat flux with a so large defect : with a $75 \%$ defect, the cooling by the heat sink is still highly efficient as the tile is cooled in less than 15 seconds.

\section{Conclusion}

Three defective tiles are observed on Tore Supra main limiter, using the infrared diagnostic monitoring the surface temperature of the component. The tiles cool slower than the others after the plasma. This amounts in 2007 to a defect rate of $0.05 \%$. Analysis shows there is no risk of water leak, even if the damage progresses 
further. Operation is then pursued, while the defects progression is monitored using the infrared diagnostic. The thermal time constants increase of a factor 3 in 2006, without consequence on plasma operation : the temperature of the defective tile is still smaller than other tiles covered by carbon deposit.

One element with a defective is removed from the vessel during the mid 2007 shut down. The defective tile shows a bond (tile/copper heat sink) cracked to $75 \%$. Tore Supra having been able to operate high power discharges with this defect, this is a demonstration that power operation is possible with a highly damaged tile.

\section{References}

[1] P. Garin, Fusion Engineering and Design, vol. $49-50$ (2000) p.89-95

[2] J. Schlosser, P. Chappuis, M. Chatelier, et Al. Fusion Engineering and Design, vol.39-40 (1998) P.235-240

[3] JJ. Cordier et Al., Effect of misalignment and braze flaws on the Tore Supra inner wall behaviour, Fusion technology 1992

[4] R. Mitteau, J.C. Vallet, R. Reichle et Al., Physica Scripta. Vol. T111, 157-162, 2004

[5] R. Mitteau, P. Chappuis, L. Moncel et al. , Jour. Nucl. Mat., Volumes 258-263, Part 1(1998), pp. 972-977 


\section{Figure captions}

Figure 1: Infrared image of the section PJ6 during cool down after \#37047. White areas are hot (1190 K), and black is cold $(400 \mathrm{~K})$.

Figure 2: Location of the defective tiles on the toroidal pump limiter

Figure 3: Plot of the relative temperature variation versus time for the extraction of the thermal time constant for defect A (\#36594).

Figure 4: Histogram of the total power injected in the plasma during the 2006 experimental campaign. Only power duration $>10$ seconds is retained for that histogram.

Figure 5: Evolution of the thermal time constants of defective tiles and reference pick-up points during 2006.

Figure 6: Photo of the damaged bond (side view of the flat tile bond). The copper heat sink is on the bottom, the carbon tile above it. The heat flux comes on the top of the tile.

Table 1: Maximum thermal delay $(\Delta \mathrm{T})$ with respect to a reference finger element. A temperature difference in the range of -3 to $3 \mathrm{~K}$ is considered normal. In the range of 3 to $6 \mathrm{~K}$, the tile is in derogation. 


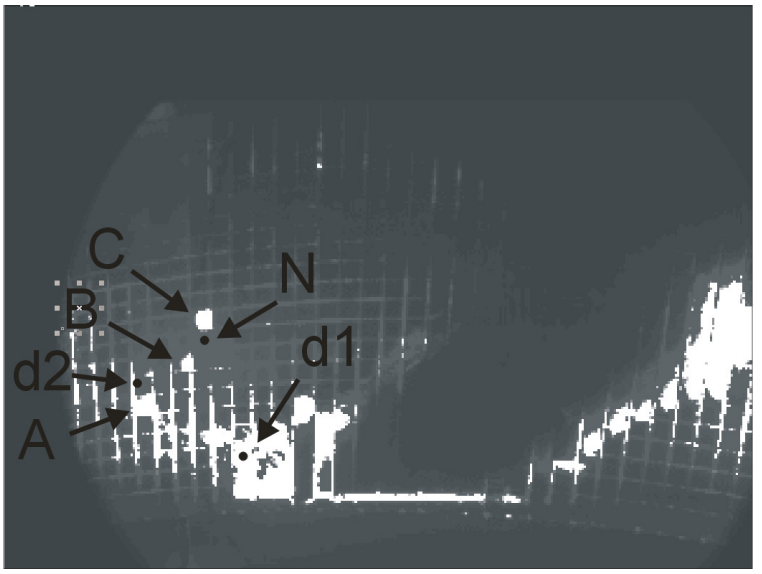

Figure 1

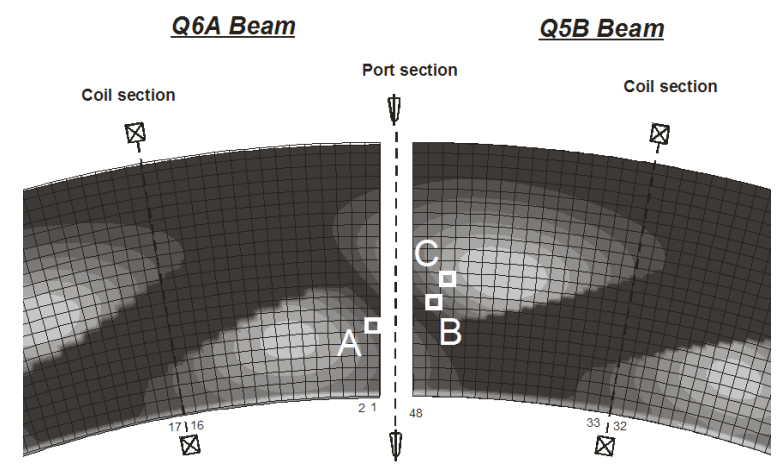

Figure 2

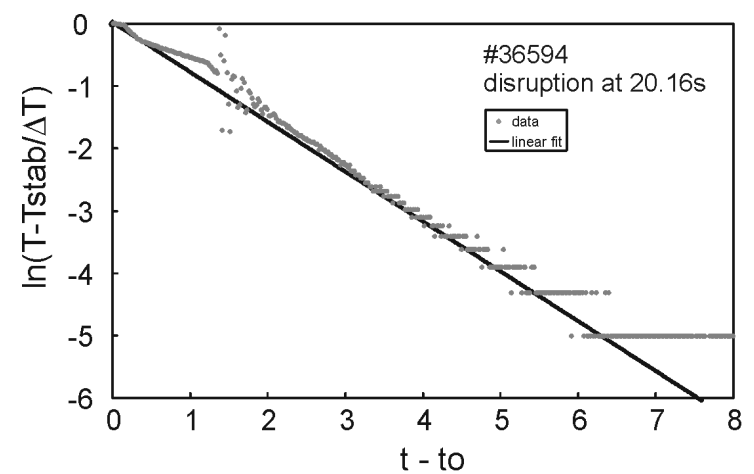

Figure 3

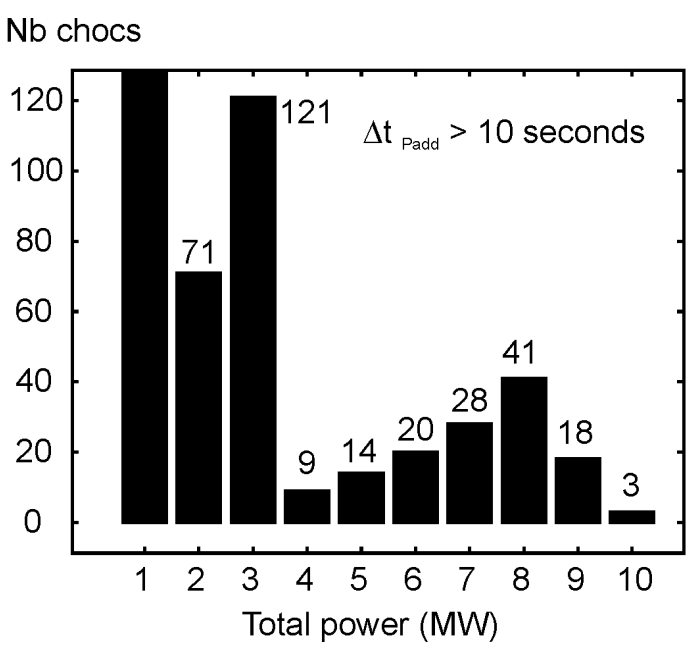

Figure 4

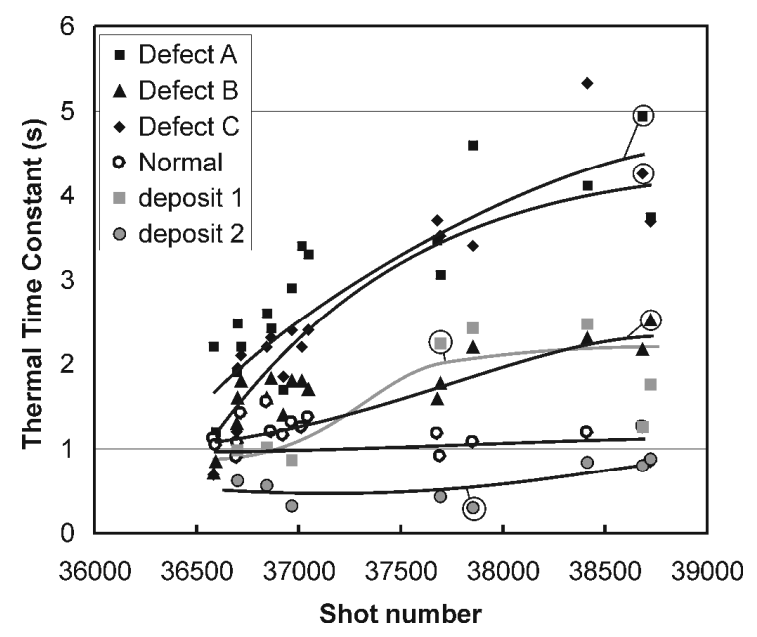

Figure 5

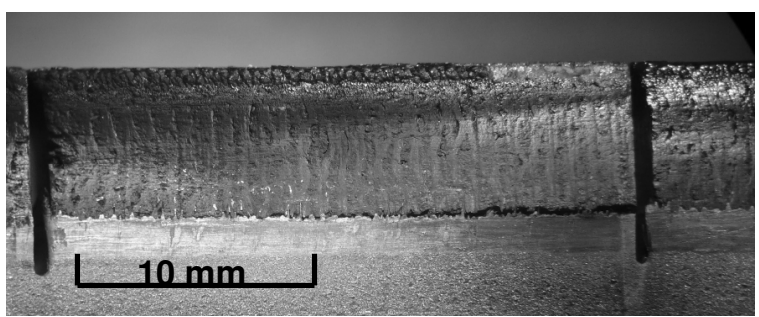

Figure 6

\begin{tabular}{|c|c|c|c|c|c|c|c|}
\hline Tile $^{\circ}$ & 2 & 3 & 4 & 5 & 6 & 7 & 8 \\
\hline$\Delta \mathrm{T}\left({ }^{\circ} \mathrm{C}\right)$ & -0.9 & 1.1 & 1.0 & 1.1 & 1.8 & 0.8 & 1.3 \\
\hline$\Delta \mathrm{T}\left({ }^{\circ} \mathrm{C}\right)$ & 0.7 & 0.8 & 0.4 & 1.7 & 28.4 & 1.2 & 0.4 \\
\hline
\end{tabular}

Table 1 
